\title{
Implementation of the law on solid waste management in Vietnam today: necessity, problem and solutions
}

\author{
Minh Duc Tran ${ }^{1 *}$, and Lyudmila Pushkareva ${ }^{2,3}$ \\ ${ }^{1}$ Vietnam Academy of Social Sciences, 10000, Nguyen Trai Street, No 477, Thanh Xuan District, Ha \\ Noi, Vietnam \\ ${ }^{2}$ North-West Institute of Management, branch of RANEPA, 199178, Sredny prospect VO, 57/43, St. \\ Petersburg, Russia \\ ${ }^{3}$ Saint Petersburg State University of Architecture and Civil Engineering, 190005, 4 Vtoraya \\ Krasnoarmeiskaya, Saint Petersburg, Russia
}

\begin{abstract}
Good management of solid waste aims to protect human health, preserve the environment, save resources and towards the sustainable development of the country. Solid waste management is expected to become increasingly complex in Vietnam due to socio-economic development and population growth. There are many factors influencing solid waste management, but it is indispensable for law to be a social management tool of the State. The provisions of the law on solid waste management and the process of law implementation need to be more and more complete in response to the increasing requirements for environmental protection. Therefore, the paper focuses on clarifying the current legal model in Vietnam that governs solid waste management relations and the process of law implementation on solid waste management in Vietnam, points out some shortcomings and problems concerning law implementation on solid waste management, thereby proposing solutions to improve the efficiency of law implementation in this field. Those are: 1/Completing decentralization in solid waste management; 2/Determining the priority order in controlling and limiting the sources of solid wastes; 3/Completing incentive mechanisms and policies, encouraging activities to reduce, reuse and recycle solid waste; 4/ Strengthening inspection, examination and handling of violations in solid waste management; 5/Promoting socialization in solid waste management.
\end{abstract}

\section{Introduction}

During the country's innovation and development, the Party and the State of Vietnam have determined a vital principle that has obtained environmental protection for sustainable development. There is no more sustainable development than the one going hand in hand with respect for natural laws. Good management of solid waste would definitely bring the country economic, social and environmental benefits.

* Corresponding author: tranminhducdanang@gmail.com 
Vietnam is in the period of economic development, industrialization and modernization with a high growth rate, especially in industrial production, services and urbanization. Vietnam's GDP has increased by an average of 6-8\% per year for many years. Along with this growth represents a substantial increase of population in urban areas. It has caused a large amount of waste from domestic activities, production, and business activities that has been discharged into nature, putting pressure on the ecological environment. The generated amount of solid waste doubled in less than 15 years. The total amount of solid waste in 2015 was estimated at over 27 million tons. The total amount of solid waste across the country is predicted to increase to 54 million tons by 2030 [4]. If solid waste is increased rapidly in number with increasingly complex components, it absolutely puts enormous pressure on waste collection and treatment.

Currently, Vietnam has been facing difficulties in solid waste collection, transportation and treatment because it has been increasing rapidly. The system of solid waste collection, transportation, treatment and disposal as well as the budget for solid waste management system hasn't been keeping up with the increasing volume of solid waste [4]. In the Decision No.491/QĐ-TTg by the Prime Minister, in 2016, the amount of solid waste collected in Vietnam was 33,167 tons, of which the total amount of common solid waste collected and treated to national standards was 27,067 tons (accounting for $81 \%$ ). Thus, there were still about 5,100 tons of solid waste which had been collected but had not been treated according to regulations, not to mention the large amount of solid waste that had not been collected, and had been polluting the soil environment [1]. In the Decision on adjusting the National Strategy issued on May 7, 2018 on integrated solid waste management by 2025 with a vision to 2050, Vietnam committed to collecting, transporting and treating solid waste with the following rates: $100 \%$ of common industrial solid waste and $90 \%$ of common domestic waste of households in urban areas, $80 \%$ of common domestic waste of households in rural areas by 2025. They are the specific objectives of the National Strategy on integrated solid waste management by 2025 with a vision to 2050 issued by the Prime Minister on May 7, 2018. However, in reality, the goals of solid waste management by 2015 set by the Government in Decision No. 2149/2009/QD-Ttg on December 17, 2009 approving the national strategy for integrated management of solid waste by 2025 with a vision to 2050 , were not yet achieved. Therefore, the adjusted content of the National Strategy on integrated solid waste management by 2025 with a vision to 2050 now is quite ambitious. Action areas and infrastructure requirements should be identified to achieve the goals, taking into account the financial arrangements for investments and the mechanism of capital recovery for waste management operations. The most essential point is to improve the legal framework and the effectiveness of law implementation on solid waste management in Vietnam [4].

\section{Materials and research methods}

The author uses statistical methods to synthesize data on solid waste, analytical and general methods to analyze the legal documents governing solid waste management, then assess law implementation on solid waste management in Vietnam. The paper also analyzes the policies, laws; studies articles, reports, data on solid waste management to set the basis to discuss recommendations that contribute to improving the efficiency of law implementation on solid waste management in Vietnam today. 


\section{Research results}

\subsection{The legal model of solid waste management in Vietnam today}

In order to analyze the current status of the legal model of solid waste management in Vietnam, it is necessary first to clarify the legal concept of solid waste management:

Firstly, law with its characteristics is a system of legal regulations governing human behavior in order to influence the relations on solid waste management, creating a legal corridor for the legal entities involved in effective solid waste management. Therefore, the law on waste management has the following basic functions: i) Regulatory function: That is a function of establishing, stabilizing and giving order for solid waste relations in accordance with the State's guidelines and in consistent with the movement and development of social life and sustainable development. ii) Protection function: That is the function of protecting relations on solid waste regulated by law through the application of protective norms according to certain legal orders and procedures for the acts violating the law on solid waste management. iii) Educational function: That is the function of impacting the law on consciousness and human behavior, directing human behavior in accordance with the requirements of the law on solid waste management and common social norms of environmental protection.

Secondly, in Vietnam, waste is understood as material discharged from production, business, services, domestic households or other activities mentioned in Term 15, Article 3, the 2014 Law on Environmental Protection. This approach is based on the sources of waste discharge. Solid waste is solid or slurry waste (also called sludge) which is discharged from production, business, service, domestic household or other activities [2]. Solid wastes can be classified into hazardous wastes, industrial wastes, municipal solid waste and specific waste such as agricultural wastes, bio-medical wastes, waste minimization.

Thirdly, there are many ways of understanding management in general, solid waste management in particular. There is a viewpoint showing that it is necessary to understand solid waste management here as State management (i.e. linking waste management completely with the responsibility of the State). However, the other viewpoint is to approach solid waste management as a closed cycle to effectively manage solid waste. According to this understanding, waste management is not only the responsibility of the State, but also the responsibility of the waste owner and the community [5]. This interpretation is reasonable. Vietnamese law is currently approaching waste management as the closed cycle. That is, waste management is the process of preventing, minimizing, monitoring, sorting, collecting, transporting, reusing, recycling and disposing of waste introduced in Term 15, Article 3, The 2014 Law on Environmental Protection. Solid waste is presently being managed according to regulations on hazardous waste, domestic waste, common industrial solid waste and specific waste such as agricultural wastes, bio-medical wastes, waste minimization.

From there, it can be understood that the law on solid waste management is a system of legal provisions governing the relationships between stakeholders in the process of solid waste prevention, mitigation, monitoring, classification, collection, transportation, reuse, recycling and treatment to protect the environment for the development of society.

In fact, waste management generally and waste management particularly are a matter of great concern in Vietnam. There have been many legal regulations on waste management issued in the legal documents, such as the 1994 Law on Environmental Protection, the 2014 Law on Environmental Protection and guiding documents for these laws.

In addition to the above documents, for solid waste management, Vietnam has issued a National Strategy on integrated solid waste management by 2025 with a vision to 2050 . This strategy was issued by the Prime Minister in 2018 in order to revise the national 
strategy for integrated solid waste management issued before. Before this document, in 1999 Vietnam issued a Strategy for solid waste management in urban and industrial areas, then in 2009 the 1999 document was replaced by the National Strategy on integrated solid waste management by 2025 with a vision to 2050 . The concept mentioned in this Strategy is integrated solid waste management, that is, the management of the entire waste life cycle from generation to final disposal. Integrated solid waste management is a common responsibility of the whole society, of which the State plays a leading role. Integrated management is carried out in an inter-regional and inter-sectoral way, ensuring economic, technical optimization, social and environmental safety. The generated solid waste must be managed and considered as a resource to be sorted and collected in accordance with the selected treatment technology. It is necessary to invest in a synchronized solid waste management system. The strategy also defined specific targets by 2025 , which would be preventing, controlling and basically restricting the generation of solid waste; minimizing environmental pollution caused by solid waste; strengthening solid waste management capacity, and simultaneously implementing measures to promote the storage, collection, transportation, reuse, recycling and treatment of solid waste; applying advanced and environmentally friendly solid waste treatment technologies suitable to local socioeconomic development conditions [2].

To effectively manage solid waste, an overall policy for solid waste management should be developed, covered from the place of generation of solid waste to the final disposal site. Therefore, the law on solid waste management must fully and appropriately adjust the following issues:

Firstly, the regulation on control of solid waste production.

The development of the economy leads to an increase in the amount of waste in the environment, solid waste can be generated at any stage of people's daily lives or in production, business and service activities. Because the process of generating solid waste is so diverse, we must control waste from generation. The control of the generation of solid waste is the main responsibility of individuals and organizations engaged in the production of solid waste. Waste generators must take action to minimize the amount of waste produced. Therefore, in order to control waste right from the source, Vietnamese law has provisions for individuals and organizations to apply measures to minimize waste generation from the source and classify, collect waste. The control also depends on each type of waste: Hazardous waste, domestic waste, common industrial waste and specific wastes from medical, construction, agriculture and transportation activities....

Secondly, regulations on solid waste collection and transportation.

Collection is a concentrated activity to temporarily classify solid waste. This is an activity aimed at preventing solid waste from being out of human control, affecting the environment and serving the further activities of solid waste management. Solid waste transportation is the process of transporting solid waste from the place of generation to the disposal place, which may be accompanied by temporary collection, storage (or gathering) and transshipment of solid waste at the place of Material Recycling Facilities or Waste Transfer Station [2].

Depending on the toxicity of solid waste, hazardous solid waste or common solid waste, the State regulates different ways of collecting and transporting. In terms of hazardous solid waste containing toxic, radioactive, infectious, flammable, explosive, corrosive, poisoning or other hazardous properties noticed in Term 13, Article 3, The 2014 Law on Environmental Protection. The regulation on collecting and transporting will be stricter than common waste.

Thirdly, regulations on solid waste disposal.

Solid waste treatment is the process of using technological and technical solutions to reduce, eliminate, isolate, quarantine, incinerate, destroy, bury waste and hazardous 
elements of waste. It can be seen that a very important stage for effective treatment of solid waste is the process of using technology and technical measures to change the nature of solid waste to create value for itself. Regeneration of solid waste value can be done through two forms that are recovering energy from waste conversion or waste recycling.

By lowering or reducing the impact of solid waste on the environment and people by sorting and re-creating its new value, it also contributes to reducing the impact of waste on the environment and people. For hazardous solid waste, the entity generating this type of solid waste must apply technological and technical measures to reduce the toxic level of waste discharged into the environment. The treatment system must match the requirements and nature of the waste. After being treated, solid wastes must ensure Vietnam's environmental standards.

\subsection{Problems and solutions to improve the effectiveness of the implementation of solid waste management law in Vietnam}

In recent years, Vietnam has made great efforts in promulgating policies and laws on solid waste management. The Government of Vietnam has set a solid waste management goal by 2050, reported in Term 2, Article 1, National Strategy on integrated solid waste management by 2025 with a vision to 2050 by the Prime Minister on May 7, 2018: "All types of generated solid waste are collected, reused, recycled and treated with advanced, environment-friendly technologies, suitable to the practical conditions of each locality, limiting the amount of solid waste to be buried." But solid waste management still has its own drawbacks, causing environmental pollution in many places. Even many areas have been seriously polluted. There are many reasons leading to that situation. One of which is that the current regulations on solid waste management are inadequate, incomplete and not close to the actual conditions. Law implementation on solid waste management in Vietnam has gradually revealed difficulties and obstacles.

From the current status of law implementation on solid waste management, there are several weaknesses that need to be improved for the efficiency of solid waste management in Vietnam. Those are:

Firstly, decentralization in solid waste management: Solid waste is managed according to the provisions of law for each type of waste, which is hazardous waste, domestic waste, common industrial solid waste and common industrial solid waste and specific waste such as agricultural wastes, bio-medical wastes, waste minimization. There are many ministries involving and solving issues on solid waste management that lead to a lack of unified and adequate management. In order to solve the shortcomings, limits and difficulties in State management of solid waste, in the Resolution No.09/NQ-CP dated February 3, 2019, the Government agreed to assign the Ministry of Natural Resources and Environment as focal agency responsible for State management of solid waste. I think the unified State management of solid waste must be implemented synchronously from the Central to local levels. At the Central level, the main agency responsible to the Government for solid waste management is the Ministry of Natural Resources and Environment. At the local level, the main agency responsible to the provincial People's Committee for solid waste management is the Department of Natural Resources and Environment. Therefore, it is necessary to revise the legal documents related to the functions and tasks of State management of solid waste of ministries, branches and localities to improve the effectiveness and efficiency of state management.

Secondly, priority should be given to the control and restriction of solid waste sources. Waste management must follow the motto: the prevention and restriction of adverse impacts on the environment are the key points. That is, it is necessary to typically prevent and limit waste generation from the place right where waste is produced. Restrictions on 
waste production must be placed in the first place, if not possible, measures must be taken to reduce the amount of waste generation. For compulsory waste generation, it must be treated. In waste treatment, recycling is a top priority for reusing waste. The next solution is the toxic elimination of waste. Only when all of these solutions have been thoroughly implemented, destruction will be the last solution.

Practically speaking, the sources of solid waste are increasingly expanding their impact on the environment due to the increase in the number and scale in Vietnam. Some sources have a very large total amount of solid waste. Yet there are also sources of waste that are not large but contain hazardous waste. Up to now, the control and restriction of pollution sources are facing many difficulties due to weak resources. Therefore, it is necessary to develop a roadmap for solid waste sources control and treatment. Determining the priority order in each phase for each type of solid waste is also a specific need. In the short term with limited resources, priority should be given to controlling waste sources with a large amount of solid waste, affecting many environmental components, such as large polluting industrial production types such as cement, iron, steel, thermoelectricity production...

Thirdly, it is necessary to develop legal regulations, complete incentive policies and mechanisms, encourage activities of reducing, reusing and recycling solid waste; promulgate appropriate roadmaps to minimize and eventually stop using non-biodegradable plastic bags. It is essential to complete the guidance on valuation methods for collection, transportation and disposal of daily-life solid waste; develop regulations on management and use of recycled products and materials for types of recycling production from solid waste [1].

Fourthly, inspection, examination and handling of violations in the field of solid waste management: To successfully attract the participation of the public sector, the legal system on solid waste management must stipulate provisions in details, including the identification of obligations and responsibilities of all stakeholders, i.e. State management agencies on solid waste and emission owners (residents, households, businesses...), terms, articles on how to treat waste at its source during collection, transportation and disposal. Relevant regulations must be enforced, which means that the authorities have to control waste management at different stages from the time of waste generation to the final disposal and penalize anyone who doesn't respect the law [4].

However, the inspection, examination and sanctioning of administrative violations in environmental protection still exist some deficiencies. The legal provisions on sanctions against administrative violations are not close to the actual situation. They only consider violations but have not considered the accumulation of fine levels when the violators commit violations many times or fail to promptly repair the damage caused. Thus the cords of discipline are not high. There are the provisions on sanctioning all violating subjects but there aren't any provisions on the objective factors leading to the violations, making the implementation of sanctions still face the dissenting opinions of the violators. The inspection and examination still faces many limitations due to the less human resources to carry out the inspection and examination. The law violations on environmental protection are increasingly complicated and difficult to detect due to administrative procedures such as: must be notified in advance, only conduct inspection during office hours...Therefore, the effectiveness of the inspection of legal compliance and timely handling of violations of all businesses are not high. Hence, the legal provisions on inspection, examination and sanctions in the field of environmental protection need to be adjusted to suit the actual situation of waste management today.

Fifthly, it is necessary to promote socialization in solid waste management. Socialization in environmental protection in general and waste management in particular is a matter of great concern of the Party and the State. The legal framework to promote socialization continues to be completed. The 2014 Law on Environmental Protection and its 
guiding documents for law implementation contain terms and articles to encourage socialization in environmental activities, such as providing many regulations on incentives, land support, taxation, fees...for entrepreneurs involving environmental protection. So far, a system of non-public environmental services has been initially established. Some thriving fields can be seen like waste collection and transportation including hazardous waste, waste treatment facilities [1]. However, in order to synchronize the socialization, an overall policy legislation framework on the development of environmental services in Vietnam and the development of the network of environmental service enterprises is needed. It is necessary to review and supplement mechanisms and policies to enhance public-private cooperation and mobilize socialized resources in environmental protection.

In addition, community-based waste collection and classification efforts should be encouraged. Role of the local community should be promoted to become a contributor to local solid waste management policies as well as a conductor, inspector and supervisor for local solid waste management.

\section{Conclusion}

Based on the research results, some conclusions can be made as follows:

Firstly, since the amount of solid waste in Vietnam is increasing, the demand for solid waste management is very urgent to protect the environment and ensure the sustainable development of the country.

Secondly, the regulations on solid waste management have been enacted in recent years, including many breakthrough regulations such as solid waste management as a closed cycle and considered common solid waste as a resource to effectively manage. The law on solid waste management has been based on each type of solid waste to make specific adjustments. However, there is still a lack of pioneer legislation in solid waste management such as the regulation on the market of solid waste. Economic tools for solid waste management and decentralization in solid waste management are still unclear.

Thirdly, in order to promote the role of the solid waste management law after being promulgated, the law must be received, respected and voluntarily implemented by entities in solid waste management relations. Implementation of the solid waste management law is a continuous process, considered an important part of the overall measures to promote environmental protection towards sustainable development. However, the process of implementing the law on solid waste management in Vietnam still has some limitations and shortcomings that need solutions to improve the implementation efficiency./.

\section{References}

1. Ministry of Natural Resources and Environment, The National Report on Environmental status 2017, Waste management topic (2017).

2. Ministry of Natural Resources and Environment, The Consolidated Document on Waste and Scrap Management (2019).

3. N. Huy Con, Builders Magazine, 12, 26-27, (2008).

4. World Bank, Evaluation of domestic solid waste and hazardous waste management, (Hong Duc Publishing House, 2018).

5. B. Duc Hien, Journal of Natural Resources and Environment, 05, 17, (2018).

6. T. Linh Huan, Journal of Democracy and Law, 1, 43-48, (2019).

7. V. Hung, Journal of Figures and Events, 12, 23-25, (2012). 
8. V. Thi Thanh Huong, N. Duc Phong, Journal of Irrigation Science and Technology, 24, 51-59, (2014).

9. Prime Minister, Approving adjustments to the National Strategy on integrated solid waste management by 2025, a vision to 2050, (2018).

10. V. Thi Duyen Thuy, Journal of democracy and law, 3, 31-36, (2016). 